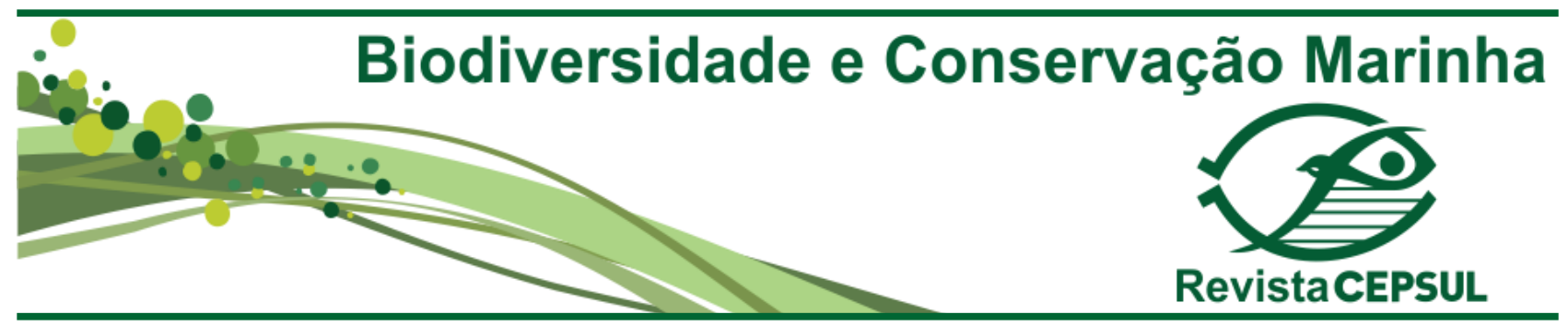

ARTIGO DE REVISÃO - ESPECIAL BABITONGA

\title{
Microbiota do Ecossistema Babitonga: importância, diagnóstico de estudo e perspectivas
}

\author{
Mariana Serwy Oortman ${ }^{1}$, SANdro Augusto Rhoden ${ }^{2}$ \& Regina Maria Miranda Gern ${ }^{1}$ \\ ${ }^{1}$ Universidade da Região de Joinville - UNIVILLE, Rua Paulo Malschitzki, 10, CEP - 89219-710, Zona Industrial Norte, Joinville, SC, \\ Brasil, mariana.serwy@gmail.com,rgern@univille.br; \\ 2 Instituto Federal Catarinense - IFC, Rodovia Duque de Caxias, 675o, CEP - 8924o-ooo, Iperoba, São Francisco do Sul, SC, Brasil, \\ sandro.rhoden@saofrancisco.ifc.edu.br.
}

Submetido em: 01/o5/2017; Aceito em: 25/o9/2018; Publicado em: 25/10/2019

Resumo. Atualmente existe uma grande pressão antrópica no Ecossistema Babitonga-SC evidenciada pela a poluição de suas águas oriundas dos despejos industriais, desmatamento, esgoto doméstico, pesca predatória, ocupação ilegal de áreas públicas, aterramentos dos bosques de mangue, avanço imobiliário e exploração turística. Além destas atividades, incluem-se os atuais e os futuros empreendimentos portuários, que já possuem licenciamento ambiental e/ou têm a possibilidade de instalação. A microbiota aquática e as que estão ligadas aos biomas associados ao Ecossistema Babitonga, em especial, restinga, manguezal, marisma, planícies de maré, são complexas no seu aspecto ecológico, uma vez que, os ambientes são heterogêneos. São praticamente inexistentes dados acadêmicos no Ecossistema Babitonga sobre a biodiversidade, que compreende especialmente a presença de bactérias e de fungos. Com o sucessivo aumento da pressão humana nos últimos 40 anos, há possibilidade que parte da biodiversidade esteja sendo perdida, sem ao menos termos o conhecimento da sua existência, ou seja, a extinção de uma rica diversidade genética. Acrescenta-se a esta perda, a subtração dos possíveis produtos biotecnológicos oriundos desta diversidade, que poderiam ser aplicados na indústria farmacêutica e na agroindústria. Este estudo teve como objetivo compilar publicações a respeito de micro-organismos no Ecossistema Babitonga e destacar sua importância ecológica e biotecnológica.

Palavras-chave: Ecossistema Babitonga; microbiota; fungos; bactérias; prospecção.

\begin{abstract}
Babitonga Bay microbiote: importance, study diagnosis and perspectives. There is currently human pressure in Babitonga Ecossystem: water pollution from industrial dumping, deforestation, domestic sewage, predatory fishing, illegal occupation of public areas, mangrove forest landfills, turistic exploration. In addition to these activities, the current and futures harbors undertakings that already have environmental licensing and / or have possibility of installation. The aquatic microbiota and those associated with the biomes Babitonga Bay, especially, restinga, mangrove, marshland and tidal plains, are
\end{abstract}


complex in their ecological aspect, since the environments are very heterogeneous. There is virtually no data on this biodiversity, which includes bacteria and fungi in particular, and the subsequent increase in human pressure over the last 40 years demonstrates the possibility that some of the biodiversity is being lost without even knowledge of its existence, that is, the extinction of a rich genetic diversity. It adds to this loss, the subtraction of the possible biotechnological products derived from this diversity that could be applied in the pharmaceutical industry and agroindustry. In this way, the present work aimed to alert and encourage the study of these microorganisms, important in their ecological aspect and biotechnological prospecting.

Keywords. Babitonga Ecossystem; Microbiota; Mangroves; Fungi; Bacteria.

\section{Introdução}

A comunidade microbiana é essencial para a manutenção e evolução dos ecossistemas (Fraune \& Bosch, 2010, Jessup et al., 2004, Rainey et al., 2000). Isto se dá por sua expressiva capacidade de adaptação e resistência em ambientes inóspitos, consequência principal de sua grande diversidade metabólica (Batista et al., 2006). Por meio de processos como a fixação do nitrogênio, amonificação e desnitrificação, solubilização de fosfato, redução de sulfato, fotossíntese e metanogênese, as bactérias mantêm cerca de 98 \% do fluxo de carbono e nitrogênio, bem como, da ciclagem de nutrientes em ambientes marinhos (Atlas \& Bartha, 1993, Sahoo \& Dhal, 2009, Taketani et al., 2010). Com isso, transformam a matéria orgânica em fontes de nutrientes que podem ser usados pelas plantas e organismos mais complexos (Bashan \& Holguin, 2002).

Em sistemas marinhos não perturbados, oscilações na composição e abundância de micro-organismos ocorrem naturalmente em função de alterações de salinidade (Pupin \& Nahas, 2014); umidade e temperatura do sedimento (Gonzalez-Acosta et al., 2006), espécies de plantas que compõem bosques de manguezal (Xing et al., 2011), agregados sedimentares (Rillig et al., 2017) e até de cinzas provenientes de erupções vulcânicas (Witt et al., 2017). Porém, a ação humana sobre os ecossistemas tem levado a alterações que afetam negativamente o microbioma das regiões marinhas (Nogueira et al., 2015). A composição da microbiota é afe- tada pela presença de áreas de cultivo de camarões (Sousa et al., 2006), por despejo de óleo e contaminantes industriais (Taketani et al., 2010) e pelo desmatamento dos bosques de mangue (Sjöling et al., 2005).

Em seus processos metabólicos, estas microcomunidades produzem compostos extracelulares como antibióticos e enzimas, que auxiliam na quebra de moléculas complexas e que podem ser utilizadas em diversas aplicações nas áreas de saúde, farmacologia, biotecnologia, entre outras (Caumo et al., 2010, Bonugli-Santos et al., 2010, Dias et al., 2009, Ghosh et al., 2007). Isolar estes microorganismos, identificá-los e buscar novas biomoléculas oriundas de seus processos metabólicos são formas de valorizar esta biodiversidade, além de contribuir para a preservação do bioma em que ocorrem.

O uso de técnicas moleculares para caracterização da comunidade microbiana, possibilitou um maior conhecimento sobre seu papel nos diversos ecossistemas por meio de sua descrição, localização e pela quantificação de populações (Horner-Devine et al., 2004). Com o aprofundamento do conhecimento utilizando a caracterização molecular foi atribuído ao grupo o conceito de "microdiversidade", que indica que a maior parte dos organismos é estreitamente relacionada geneticamente, porém ecologica e fisiologicamente distinta dentro de sua diversidade funcional (Garcia-Martinez \& Rodriguez-Valera, 2000, Schloter et al., 2000, Acinas et al., 2004, Zimmerman et al., 2013, 
Larkin \& Martiny, 2017). Leva-se em consideração que a diversidade microbiana é cerca de 1000 vezes maior do que era estimado com métodos dependentes de cultivo (Pace, 1997). Com isso, iniciativas na área de pesquisa para gerar conhecimento acerca desta diversidade vêm sendo realizados no mundo. Um exemplo é o Censo Internacional de Micróbios Marinhos (ICoMM) que visa "catalogar toda a diversidade conhecida de organismos unicelulares (Bactérias, Archaea, Protistas e vírus associados), explorar e descobrir a diversidade microbiana desconhecida, e colocar esse conhecimento em contextos ecológicos e evolutivos apropriados" (Sogin \& Leew, 2004).

No Brasil, o Projeto Microbioma Brasileiro, visa reunir os dados coletados no país em uma base de dados e padronizar as técnicas de amostragem e processamento para auxiliar na comparação dessas comunidades (Pylro et al., 2014). A diversidade microbiana pode apresentar variações latitudinais, na profundidade e no tipo de ambiente (Thompson et al., 2011). Atualmente os estudos moleculares são ferramentas indispensáveis para análises de biodiversidade microbiana, uma vez que, uma grande parte dos micro-organismos é de difícil cultivo em laboratório em função, principalmente, de seu desenvolvimento em consórcios. Para os estudos de bioprospecção são necessárias a utilização de ferramentas e estudos prévios com o objetivo de cultivar os micro-organismos em laboratório. Para os estudos de bioprospecção são necessárias a utilização de ferramentas e estudos prévios com o objetivo de cultivar os micro-organismos em laboratório (Garcia et al., 2016).

No norte do Estado de Santa Catarina está localizado o Ecossistema Babitonga, região que compõe o maior complexo estuarino do litoral de Santa Catarina. Seu entorno é rodeado por florestas de mangue e importantes remanescentes de Mata Atlântica e restinga (Knie, 2002). Cerca de $75 \%$ dos bosques de manguezais do Estado de Santa Catarina pertencem à região que, em termos de cobertura vegetal, é o limite austral deste ecossistema no Oceano Atlântico. Historicamente, ao longo de um processo de ocupação desordenada, a regi- ão sofreu degradações de seus ecossistemas, especialmente manguezais. A ocupação ilegal, o assoreamento acelerado por supressão ilegal da vegetação, a pesca predatória e caça clandestina, a ocupação ilegal das áreas públicas, a poluição hídrica por esgotos domésticos e industriais e o despejo de materiais sólidos são algumas das atividades que mais ameaçam o equilíbrio da região (Brasil, 2007). Nas margens do Ecossistema também está inserido o maior polo industrial do Estado de Santa Catarina, na cidade de Joinville; os portos de São Francisco do Sul e Itapoá; e um terminal de transporte de petróleo em São Francisco do Sul. Segundo o Ministério do Meio Ambiente (2007), a região é candidata à criação de uma área protegida de uso sustentável. A iniciativa se dá pelo crescente estímulo ao ecoturismo na região, pela força da pesca artesanal ainda presente e para a preservação das espécies de importância comercial e ecológica.

O desequilíbrio ecológico da microbiota é fator potencial para o aparecimento de doenças nos animais que vivem na Babitonga, principalmente os que são utilizados para o consumo humano (problemas com intoxicações alimentares e as grandes perdas na maricultura, são exemplos). Além destas situações, as alterações populacionais da microbiota, alteram a qualidade físico-química da água, modificando profundamente as cadeias alimentares.

Este trabalho de revisão visa mapear e diagnosticar os trabalhos realizados na Babitonga relacionados à diversidade microbiana $\mathrm{e}$ à bioprospecção de compostos oriundos desta diversidade, a fim de identificar lacunas de conhecimento para orientar futuros estudos sobre o tema, fornecendo mais dados para a conservação deste ecossistema.

\section{Metodologia}

Foram utilizadas as ferramentas de pesquisa on-line: "Periódicos CAPES", "Google Scholar" e "Science Direct". Os termos para realizar pesquisas na literatura foram: "Micro AND Babitonga", "Microorganism AND Babitonga", "Bacteria AND Babitonga" e somente "Babitonga". Ainda, foram pesquisados os rela- 
tórios de balneabilidade da Fundação do Meio Ambiente de Santa Catarina (FATMA) e relatórios de impacto ambiental solicitados às empresas de consultoria ambiental.

\section{Resultados e discussão}

Após uma extensa pesquisa bibliográfica, pode-se constatar que praticamente não há dados publicados sobre a microbiota do Ecossistema Babitonga. A única exceção, são os dados de balneabilidade das praias da região fornecidos em relatórios pela Fundação do Meio Ambiente de Santa Catarina (FATMA, 2018). As pesquisas de balneabilidade apresentam o número mais provável de organismos (NMP) da espécie Escherichia coli (coliformes fecais) a cada $100 \mathrm{~mL}$ de amostra de água coletada (FATMA, 2018). Por ser uma extensa lista de dados, compilados desde 1976, foram apresentados os valores máximos e mínimos sazonais de coliformes fecais dos últimos 5 anos nas praias do Ecossistema Babitonga na tabela 1. Os maiores valores para todos os anos, foram registrados no Verão e na Primavera, épocas em que as praias da região recebem milhares de turistas e, consequentemente, há um aumento na descarga de esgoto doméstico em suas águas. Estes dados fornecem uma ideia do grau de contaminação por esgoto nas águas da Babitonga e reforçam o alerta do Atlas de Saneamento Básico (IBGE, 2011) sobre a necessidade de melhoria do alcance dos sistemas de coleta e tratamento de esgotos no Brasil.

Os trabalhos acadêmicos encontrados no levantamento de dados são voltados para a caracterização da microbiota dos manguezais da região, apesar da diversidade de ecossistemas que a Babitonga abriga (restinga, manguezal, marisma, planícies de maré). Há alguns estudos sendo conduzidos por alunos de graduação e pós-graduação da Universidade da Região de Joinville - Campus Joinville, que iniciaram em 2017, que visam caracterizar a microbiota presente em manguezais do Ecossistema da Babitonga e avaliar o potencial de bioprospecção dos microrganismos encontrados. Assim como o estudo conduzidos pelo Dr. Sandro Augusto Rhoden, do Instituto Federal Catarinen- se, Campus São Francisco do Sul, que visam primeiramente estudar a biodiversidade publicada até o presente momento, com objetivo de futuros estudos de prospecção biotecnológica, com foco no estudo in silico de marcadores moleculares de fungos e bactérias endofíticos de plantas de mangue. Os resultados obtidos nestes estudos ainda não foram publicados.

Levando em consideração que a diversidade microbiana é um reservatório de novos genes e que representam papéis importantes nos ecossistemas marinhos e também na sua remediação, torna-se importante caracterizar a microbiota e as suas possíveis aplicações biotecnológicas. A importância reside também no fato de ser um ambiente altamente impactado e a tendência que estes impactos sejam maiores nos próximos anos.

\section{Conclusão}

A microbiota aquática do Ecossistema Babitonga possivelmente é complexa no seu aspecto ecológico, uma vez que os ambientes são heterogêneos, no entanto, ainda permanece desconhecida. Devido a inexistência de dados e o sucessivo aumento da pressão humana nos últimos 40 anos, é possível que, parte da biodiversidade esteja sendo perdida, sem ao menos ter-se o conhecimento da sua existência, ou seja, acontece a extinção de uma rica diversidade genética. Acrescenta-se a esta perda, a subtração dos possíveis produtos biotecnológicos oriundos desta diversidade, que poderiam ser aplicados na indústria farmacêutica e na agroindústria.

Assim, é necessário e urgente o desenvolvimento de pesquisas que tenham como objetivo primário o conhecimento da microdiversidade, em diversos pontos do Ecossistema Babitonga e nos mais diversos biomas associados, para estabelecer o status da diversidade atual para que, em segundo momento, sejam realizados estudos sobre o isolamento, identificação e possível prospecção de microorganismos deste complexo ambiente 
Tabela 1. Registros sazonais dos valores de Escherichia coli nas águas das cidades do entorno do Ecossistema Babitonga de acordo com a Fundação do Meio Ambiente de Santa Catarina (FATMA).

\begin{tabular}{|c|c|c|c|c|c|}
\hline \multirow[t]{2}{*}{ Município } & \multirow[t]{2}{*}{ Local } & \multirow[t]{2}{*}{ Ano } & \multirow[t]{2}{*}{ Estação } & \multicolumn{2}{|c|}{$\begin{array}{c}\text { E.coli } \\
(\mathrm{NMP} / \mathbf{1 0 0 m L})\end{array}$} \\
\hline & & & & Mínimo & Máximo \\
\hline \multirow{36}{*}{ Barra do Sul } & \multirow{18}{*}{ Canal do Linguado } & \multirow{4}{*}{2014} & Verão & 1 & 3500 \\
\hline & & & Outono & 230 & 1400 \\
\hline & & & Inverno & 20 & 991 \\
\hline & & & Primavera & 31 & 3873 \\
\hline & & \multirow{4}{*}{2015} & Verão & 104 & 24196 \\
\hline & & & Outono & 10 & 24196 \\
\hline & & & Inverno & 10 & 19863 \\
\hline & & & Primavera & 327 & 24196 \\
\hline & & \multirow{4}{*}{2016} & Verão & 10 & 24196 \\
\hline & & & Outono & 135 & 9606 \\
\hline & & & Inverno & 41 & 17329 \\
\hline & & & Primavera & 10 & 24196 \\
\hline & & \multirow{4}{*}{2017} & Verão & 10 & 24196 \\
\hline & & & Outono & 369 & 24196 \\
\hline & & & Inverno & 135 & 17329 \\
\hline & & & Primavera & 10 & 24196 \\
\hline & & \multirow{2}{*}{2018} & Verão & 10 & 24196 \\
\hline & & & Outono & 30 & 1178 \\
\hline & \multirow{18}{*}{ Praia de Barra do Sul } & \multirow{4}{*}{2014} & Verão & 12,8 & 230 \\
\hline & & & Outono & 230 & 230 \\
\hline & & & Inverno & 10 & 20 \\
\hline & & & Primavera & 10 & 426 \\
\hline & & \multirow{4}{*}{2015} & Verão & 10 & 98 \\
\hline & & & Outono & 10 & 350 \\
\hline & & & Inverno & 10 & 395 \\
\hline & & & Primavera & 10 & 241 \\
\hline & & \multirow{4}{*}{2016} & Verão & 10 & 1211 \\
\hline & & & Outono & 10 & 132 \\
\hline & & & Inverno & 10 & 20 \\
\hline & & & Primavera & 10 & 173 \\
\hline & & \multirow{4}{*}{2017} & Verão & 10 & 530 \\
\hline & & & Outono & 10 & 41 \\
\hline & & & Inverno & 10 & 10 \\
\hline & & & Primavera & 10 & 52 \\
\hline & & \multirow{2}{*}{2018} & Verão & 10 & 107 \\
\hline & & & Outono & 10 & 272 \\
\hline \multirow{8}{*}{ Itapoá } & \multirow{8}{*}{ Praia de Itapoá } & \multirow{4}{*}{2014} & Verão & 6,3 & 2419,6 \\
\hline & & & Outono & 20 & 230 \\
\hline & & & Inverno & 10 & 86 \\
\hline & & & Primavera & 10 & 148 \\
\hline & & \multirow{4}{*}{2015} & Verão & 10 & 1187 \\
\hline & & & Outono & 10 & 292 \\
\hline & & & Inverno & 10 & 8664 \\
\hline & & & Primavera & 10 & 2142 \\
\hline
\end{tabular}


Tabela 1. Continuação.

\begin{tabular}{|c|c|c|c|c|c|}
\hline \multirow[t]{2}{*}{ Município } & \multirow[t]{2}{*}{ Local } & \multirow[t]{2}{*}{ Ano } & \multirow[t]{2}{*}{ Estação } & \multicolumn{2}{|c|}{$\begin{array}{c}\text { E.coli } \\
(\mathrm{NMP} / \mathbf{1 0 0 m L})\end{array}$} \\
\hline & & & & Mínimo & Máximo \\
\hline \multirow{10}{*}{ Itapoá } & \multirow{10}{*}{ Praia de Itapoá } & \multirow{4}{*}{2016} & Verão & 10 & 2851 \\
\hline & & & Outono & 10 & 573 \\
\hline & & & Inverno & 10 & 86 \\
\hline & & & Primavera & 10 & 2613 \\
\hline & & \multirow{4}{*}{2017} & Verão & 10 & 19863 \\
\hline & & & Outono & 10 & 689 \\
\hline & & & Inverno & 10 & 368 \\
\hline & & & Primavera & 10 & 1376 \\
\hline & & \multirow{2}{*}{2018} & Verão & 10 & 5172 \\
\hline & & & Outono & 10 & 158 \\
\hline \multirow{18}{*}{ Joinville } & \multirow{18}{*}{ Praia do Vigorelli } & \multirow{4}{*}{2014} & Verão & 4 & 1300 \\
\hline & & & Outono & 230 & 3000 \\
\hline & & & Inverno & 121 & 12997 \\
\hline & & & Primavera & 52 & 1067 \\
\hline & & \multirow{4}{*}{2015} & Verão & 187 & 1860 \\
\hline & & & Outono & 460 & 1281 \\
\hline & & & Inverno & 241 & 1169 \\
\hline & & & Primavera & 332 & 12033 \\
\hline & & \multirow{4}{*}{2016} & Verão & 216 & 6131 \\
\hline & & & Outono & 312 & 3076 \\
\hline & & & Inverno & 31 & 389 \\
\hline & & & Primavera & 63 & 2755 \\
\hline & & \multirow{4}{*}{2017} & Verão & 63 & 12033 \\
\hline & & & Outono & 201 & 1145 \\
\hline & & & Inverno & 41 & 331 \\
\hline & & & Primavera & 63 & 3654 \\
\hline & & \multirow{2}{*}{2018} & Verão & 63 & 9208 \\
\hline & & & Outono & 52 & 1918 \\
\hline \multirow{18}{*}{$\begin{array}{l}\text { São Francisco do } \\
\text { Sul }\end{array}$} & \multirow{18}{*}{ Praia do Capri } & \multirow{4}{*}{2014} & Verão & 9,2 & 76,9 \\
\hline & & & Outono & 230 & 230 \\
\hline & & & Inverno & 10 & 345 \\
\hline & & & Primavera & 10 & 663 \\
\hline & & \multirow{4}{*}{2015} & Verão & 10 & 443 \\
\hline & & & Outono & 218 & 609 \\
\hline & & & Inverno & 75 & 663 \\
\hline & & & Primavera & 10 & 602 \\
\hline & & \multirow{4}{*}{2016} & Verão & 10 & 3076 \\
\hline & & & Outono & 10 & 98 \\
\hline & & & Inverno & 10 & 561 \\
\hline & & & Primavera & 10 & 4611 \\
\hline & & & Verão & 10 & 1539 \\
\hline & & 2017 & Outono & 41 & 86 \\
\hline & & 2017 & Inverno & 20 & 63 \\
\hline & & & Primavera & 31 & 160 \\
\hline & & 2018 & Verão & 10 & 168 \\
\hline & & 2010 & Outono & 10 & 246 \\
\hline
\end{tabular}


Tabela 1. Continuação.

\begin{tabular}{|c|c|c|c|c|c|}
\hline \multirow[t]{2}{*}{ Município } & \multirow[t]{2}{*}{ Local } & \multirow[t]{2}{*}{ Ano } & \multirow[t]{2}{*}{ Estação } & \multicolumn{2}{|c|}{$\begin{array}{c}\text { E.coli } \\
(\mathrm{NMP} / \mathbf{1 0 0 m L})\end{array}$} \\
\hline & & & & Mínimo & Máximo \\
\hline \multirow{44}{*}{$\begin{array}{l}\text { São Francisco do } \\
\text { Sul }\end{array}$} & \multirow{18}{*}{ Praia da Enseada } & \multirow{4}{*}{2014} & Verão & 2 & 437,4 \\
\hline & & & Outono & 230 & 300 \\
\hline & & & Inverno & 20 & 402 \\
\hline & & & Primavera & 10 & 7270 \\
\hline & & \multirow{4}{*}{2015} & Verão & 31 & 7270 \\
\hline & & & Outono & 10 & 98 \\
\hline & & & Inverno & 10 & 134 \\
\hline & & & Primavera & 31 & 1291 \\
\hline & & \multirow{4}{*}{2016} & Verão & 10 & 6867 \\
\hline & & & Outono & 10 & 422 \\
\hline & & & Inverno & 10 & 368 \\
\hline & & & Primavera & 10 & 399 \\
\hline & & \multirow{4}{*}{2017} & Verão & 10 & 4611 \\
\hline & & & Outono & 41 & 1439 \\
\hline & & & Inverno & 10 & 1616 \\
\hline & & & Primavera & 10 & 5794 \\
\hline & & \multirow{2}{*}{2018} & Verão & 10 & 24196 \\
\hline & & & Outono & 20 & 197 \\
\hline & \multirow{18}{*}{ Praia de Itaguaçu } & \multirow{4}{*}{2014} & Verão & 7 & 300 \\
\hline & & & Outono & 10 & 230 \\
\hline & & & Inverno & 10 & 144 \\
\hline & & & Primavera & 10 & 908 \\
\hline & & & Verão & 30 & 345 \\
\hline & & 2015 & Outono & 20 & 107 \\
\hline & & 2015 & Inverno & 63 & 265 \\
\hline & & & Primavera & 20 & 583 \\
\hline & & & Verão & 10 & 148 \\
\hline & & 0016 & Outono & 10 & 122 \\
\hline & & 2010 & Inverno & 10 & 63 \\
\hline & & & Primavera & 10 & 201 \\
\hline & & & Verão & 10 & 809 \\
\hline & & 2017 & Outono & 10 & 2224 \\
\hline & & $201 /$ & Inverno & 10 & 10 \\
\hline & & & Primavera & 10 & 122 \\
\hline & & 0018 & Verão & 10 & 1918 \\
\hline & & 2010 & Outono & 10 & 41 \\
\hline & & & Verão & 6 & 16000 \\
\hline & & 2014 & Outono & 230 & 1300 \\
\hline & & 2014 & Inverno & 168 & 8664 \\
\hline & Praia de Paulas & & Primavera & 130 & 6167 \\
\hline & rara ue 1 auras & & Verão & 86 & 2098 \\
\hline & & 2015 & Outono & 246 & 5475 \\
\hline & & J & Inverno & 173 & 1401 \\
\hline & & & Primavera & 35,5 & 17329 \\
\hline
\end{tabular}


Tabela 1. Continuação.

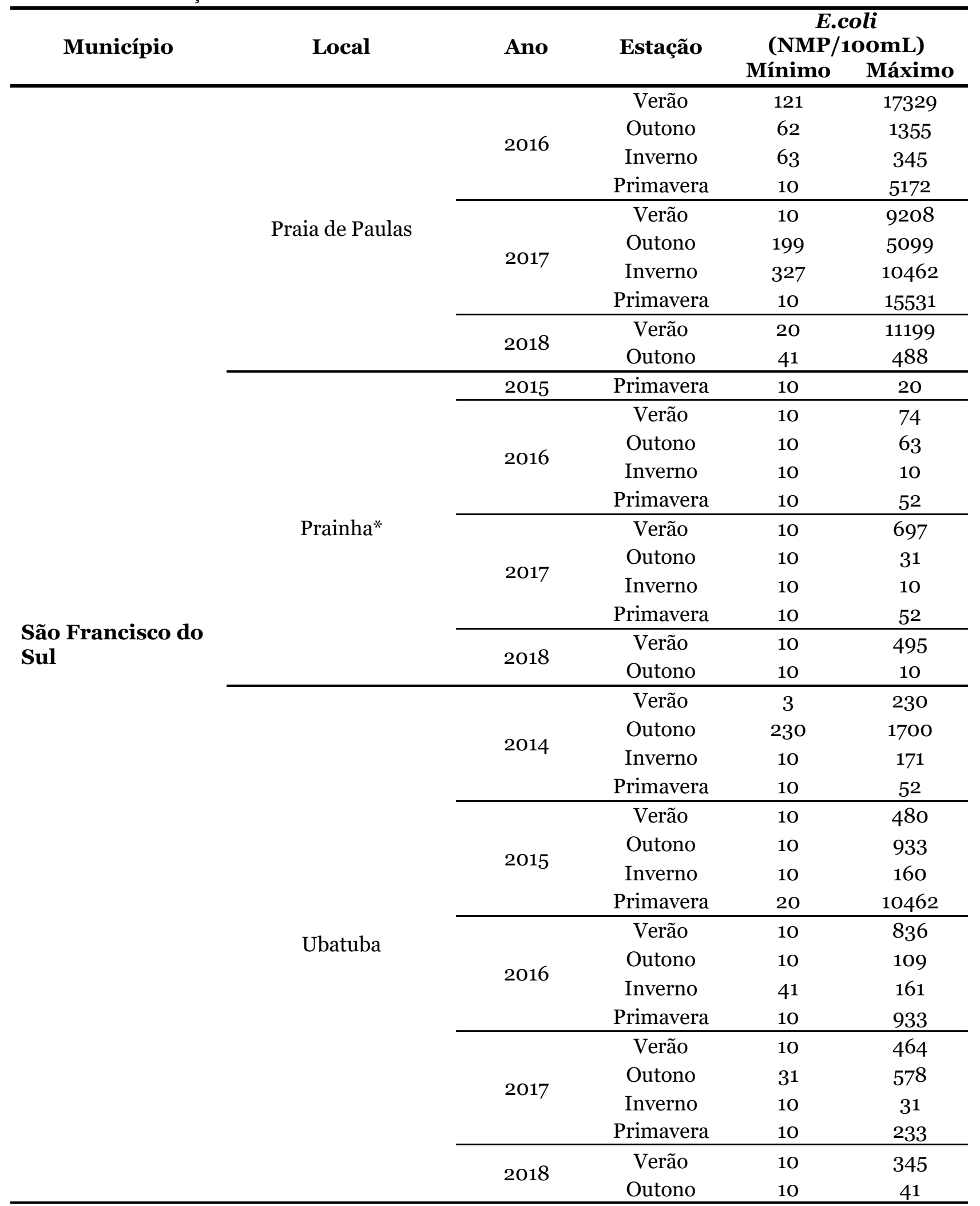

\section{Referências Bibliográficas}

ACINAS, S. G., MARCELINO, L. A., KLEPACCERAJ, V., \& POLZ, M. F. 2004. Divergence and redundancy of $16 \mathrm{~S}$ rRNA sequences in genomes with multiple rRNA operons. J. of Bact., 186: 2629-2635.

ATLAS, R. M. \& BARTHA, R. 1993. Microbial Ecology Fundamentals and Applications. 3rd 
ed. Redwood City, The Benjamin/Cummings Publishing. $561 \mathrm{p}$.

BASHAN, Y. \& HOLGUIN, G. 2002. Plant growth -promoting bacteria: a potential tool for arid mangrove reforestation. Trees, 16: 159-166.

BATISTA S. B., MOUNTEER A. H., AMORIM F. R. \& TÓTOLA M. R. 2006. Isolation and characterization of biosurfactant/ bioemulsifier-producing bacteria from petroleum contaminated sites. Bioresour Technol., 97(6): 868-75.

BONUGLI-SANTOS, R. C., DURRANT, L. R., SILVA, M. \& SETTE, L. D. 2010. Production of laccase, manganese peroxidase and lignin peroxidase by Brazilian marine-derived fungi. Enzyme Microb. Technol., 46: 32-37.

BRASIL, 2007. Portaria MMA no o9/2007. Lista das áreas prioritárias para conservação da biodiversidade. Diário Oficial [da] União, Brasília, DF, 24 de jan. de 2007.

CAUMO, K., DUARTE, M., CARGNIN, S. T., RIBEIRO, V.B, TASCA, T., MACEDO, J.A. 2010. Resistência bacteriana no meio ambiente e implicações na clínica hospitalar. Rev. Liberato, 11 (16): 89-188.

DIAS, A. C. F., ANDREOTE, F. D., DINIANDREOTE, F., LACAVA, P. T., SÁ, A. L. B., MELO, I. S., AZEVEDO, J. L. \& ARAÚJO, W. L. 2009. Diversity and biotechnological potential of culturable bacteria from Brazilian mangrove sediment. World J. Microbiol. Biotechnol., 25(7): 1305-1311.

FUNDAÇAO DO MEIO AMBIENTE DE SANTA CATARINA - FATMA. 2018. Informações. Disponível em: < http:// www.fatma.sc.gov.br/conteudo/informacoes2>. Acesso em: 27 de jun. de 2018.

FRAUNE, S. \& BOSCH, T. C. G. 2010. Why bacteria matter in animal development and evolution. Bioessays, 37: 571-580.

GARCIA-MARTINEZ, J. \& RODRIGUEZVALERA, F. 2000. Microdiversity of uncultured marine prokaryotes: the SAR11 cluster and the marine Archaea of Group I. Mol. Ecol., 9: 935- 948.

GARCIA, A., POLONIO, J. C., POLLI, A. D., SANTOS, C. M., RHODEN, S. A., QUECINE,
M. C., AZEVEDO, J. L. \& PAMPHILE, J. A. 2016. Rhizosphere bacteriome of the medicinal plant Sapindus saponaria L. revealed by pyrosequencing. Genet. Mol Res., 15(4): gmr15049020.

GHOSH, A., MAITY, B., CHAKRABARTI, K. \& CHATTOPADHYAY, D. 2007. Bacterial diversity of East Calcutta Wet Land Area: Possible identification of potential bacterial population for different biotechnological uses. Microb. Ecol., 54(3): 452-459.

GONZALEZ-ACOSTA, B., BASHAN, Y., HERNANDEZ-SAAVEDRA, N. Y., ASCENCIO, F. \& DE LA CRUZ-AGÜEROET, G. 2006. Seasonal seawater temperature as the major determinant for populations of culturable bacteria in the sediments of an intact mangrove in an arid region. FEMS Microbiol. Ecol., 55: 311 -321 .

HORNER-DEVINE, M.C., CARNEY, K.M., \& BOHANNAN, B. J. 2004. An ecological perspective on bacterial biodiversity. P. Roy. Soc. Lond. B Bio. 271: 113-122.

JESSUP, C. M., KASSEN, R., FORDE, S. E., KERR, B., BUCKLING, A., RAINEY, P. B. \& BOHANNAN, B. J. M. 2004. Big questions, small worlds: microbial model systems in ecology. Trends Ecol. Evol., 19(4): 189-197.

KNIE, J. L. W. 2002. Atlas Ambiental da Região de Joinville: Complexo Hídrico da Baía da Babitonga. Florianópolis, FATMA/GTZ. 187p.

LARKIN, A. A. \& MARTINY, A. C. 2017. Microdiversity shapes the traits, niche space, and biogeography of microbial taxa. Environ. Microbiol. Rep., 9(2): 55-70.

NOGUEIRA, V. L. R., ROCHA, L. L., COLARES, G. B., ANGELIM, A. L., NORMANDO, L. R. O., CANTÃO, M. E., AGNEZ-LIMA, L. F., ANDREOTE, F. D. \& MELO, V. M. M. 2015. Microbiomes and potential metabolic pathways of pristine and anthropized Brazilian mangroves. Reg. Stud. Mar. Sci., 2: 56-64.

PACE, N.R. 1997. A molecular view of microbial diversity and the biosphere. Science, 276 (5313): 734-40.

PUPIN, B. \& NAHAS, E. 2014. Microbial populations and activities of mangrove, restinga and Atlantic forest soils from Cardoso Island, 
Braz. J. Microbiol., 116(4): 851-864.

PYLRO, V. S., ROESCH, L. F. W., ORTEGA, J. M., AMARAL, A. M., TÓTOLA, M. R., HIRSCH, P. R., ROSADO, A. S., GÓES-NETO, A., COSTA-DA-SILVA, A. L., ROSA, C. A., MORAIS, D. K., ANDREOTE, F. D., DUARTE, G. F., MELO, I. S., SELDIN, L., LAMBAIS, M. R., HUNGRIA, M., PEIXOTO, R. S., KRUGER, R. H., TSAI, S. M. \& AZEVEDO, V. 2014. Brazilian Microbiome Project: Revealing the Unexplored Microbial Diversity-Challenges and Prospects. Microb. Ecol., 67: 237-241.

RAINEY, P. B., BUCKLING, A., KASSEN, R. \& TRAVISANO, M. 200o. The emergence and maintenance of diversity: insights from experimental bacterial populations. Tree, 15: 243-247.

RILLIG, M. C., MULLER, L. A. H., LEHMANN, A. 2017. Soil aggregates as massively concurrent evolutionary incubators. ISME J.:1-6.

SAHOO, K. \& DHAL, N. K. 2009. Potential microbial diversity in mangrove ecosystems: a review. Indian J. Mar. Sci., 38(2): 249-256.

SCHLOTER, M., LEBUHN, M., HEULIN, T. \& HARTMANN, A. 2000. Ecology and evolution of bacterial microdiversity. FEMS Microb. Rev., 24: 647-660.

SJÖLING, S., MOHAMMED, S. M., LYIMO, T. J. \& KYARUZI, J. J. 2005. Benthic bacterial diversity and nutrient processes in mangroves: Impact of deforestation. Estuar. Coast. Shelf Sci., 63(3): 397-406.

SOGIN, M. L. \& LEEW, J. W. 2004. International Census of Marine Microbes (ICOMM): The original ICoMM proposal. Disponível em: <http://icomm.mbl.edu/about/ icomm_proposal.html >. Acesso em: 15 abr. 2017.

SOUSA, O. V., MACRAE, A., MENEZES, F. G. R., GOMES, N. C. M., VIEIRA, R. H. S. F. \& MENDONÇA-HAGLER, L. C. S. 2006. The impact of shrimp farming effluent on bacterial communities in mangrove waters, Ceará, Brazil. Mar. Pol. Bul., 52(12): 1725-1734.

TAKETANI, R. G., YOSHIURA, C. A., DIAS, A. C. F., ANDREOTE, F. D. \& TSAI, S. M. 2010. Diversity and identification of methanogenic archaea and sulphate-reducing bacteria in sediments from a pristine tropical mangrove. Antonie van Leeuwenhoek, Int. J. Gen. Mol. Microbiol., 97 (4): 401-411.

THOMPSON, F.L., BRUCE, T., GONZALEZ, A., CARDOSO, A., CLEMENTINO, M., COSTAGLIOLA, M., HOZBOR, C., OTERO, E., PICCINI, C., PERESSUTTI, S. SCHMIEDER, R., EDWARDS, R., SMITH, M., TAKIYAMA, R., PARANHOS, R \& ARTIGAS, L. F. 2011. Coastal bacterioplankton community diversity along a latitudinal gradient in Latin America by means of V6 tag pyrosequencing. Arch Microbiol. 193(2): 105-14.

WITT, V., AYRIS, P. M., DAMBY, D. E., CIMARELLI, C., KUEPPERSS, U., DINGWELL, D. B. \& WÖRHEIDE, G. 2017. Volcanic ash supports a diverse bacterial community in a marine mesocosm. Geobiol., 15: 453-463.

XING, X. K., CHEN, J., XU, M. J., LIN, W. H. \& GUO, S. X. 2011. Fungal endophytes associated with Sonneratia (Sonneratiaceae) mangrove plants on the south coast of China. For. Pathol., 41(4): 334-340.

ZIMMERMAN, A.E., MARTINY, A.C. \& ALLISON, S.D. 2013. Microdiversity of extracellular enzyme genes among sequenced prokaryotic genomes. ISME J 7: 1187-1199. 